\title{
Phosphorus Removal from Eutrophic Waters with an Aluminium Hybrid Nanocomposite
}

\author{
M. Oliveira $\cdot$ A. V. Machado $\cdot$ R. Nogueira
}

Received: 2 December 2011 / Accepted: 12 June 2012 /Published online: 27 June 2012

(C) Springer Science+Business Media B.V. 2012

\begin{abstract}
An excess of phosphorus (P) is the most common cause of eutrophication of freshwater bodies. Thus, it is imperative to reduce the concentration of $\mathrm{P}$ to prevent harmful algal blooms. Moreover, recovery of $\mathrm{P}$ has been gaining importance because its natural source will be exhausted in the near future. Therefore, the present work investigated the removal and recovery of phosphate from water using a newly developed hybrid nanocomposite containing aluminium nanoparticles (HPN). The HPN-Pr removes $0.80 \pm 0.01 \mathrm{mg} \mathrm{P} / \mathrm{g}$ in a $\mathrm{pH}$ interval between 2.0 and 6.5. The adsorption mechanism was described by a Freundlich adsorption model. The material presented good selectivity for phosphate and can be regenerated using an $\mathrm{HCl}$ dilute solution. The factors that contribute most to the attractiveness of HPN-Pr as a phosphate sorbent are its moderate removal capacity, feasible production at
\end{abstract}

M. Oliveira $(\bowtie) \cdot$ A. V. Machado

IPC-Institute of Polymers and Composites/I3N,

Department of Polymers Engineering, University of Minho,

Campus de Azurém,

4800-058 Guimarães, Portugal

e-mail: moliveira@dep.uminho.pt

R. Nogueira

IBB - Institute for Biotechnology and Bioengineering,

Center of Biological Engineering, University of Minho,

Campus de Gualtar,

4710-057 Braga, Portugal

e-mail: regina@deb.uminho.pt industrial scale, reuse after regeneration and recovery of phosphate.

Keywords Eutrophication · Phosphorus removal · Hybrid nanocomposites · Aluminium

\section{Introduction}

Correll (1999), in his review work, reported that the excess of $\mathrm{P}$ is the most common cause of eutrophication in freshwater bodies, namely, lakes, reservoirs, streams and headwaters of estuarine systems (Correll 1999). The high input of $P$ to water bodies that has been observed in the last decades results from two main sources: the growth of human population and inherent activities (point source of $\mathrm{P}$ ) and the excessive use of fertilizers containing $\mathrm{P}$ to increase the production of crops (non-point source of $\mathrm{P}$ ). Nowadays, the classification of the trophic state of freshwater bodies used in most European countries is based on the concentration of $\mathrm{P}$ and algal density present in the water column. In fact, a concentration of $\mathrm{P}$ of $30 \mu \mathrm{g} / \mathrm{L}$ may be enough to provoke the excessive growth of aquatic plants and algal blooms (Carmichael 1991; Selman and Greenhalg 2009; Zheng et al. 2011). Hickey and Gibbs (2009) reported that $51 \%$ of the lakes in Great Britain with $<1$ ha required the implementation of $\mathrm{P}$ reduction measures to achieve the "good ecological status" prescribed by the Water Framework Directive until 2015 (Hickey and Gibbs 
2009). A study at global scale done by The Water Wheel reported that $54 \%$ of the lakes and reservoirs in Asia are impaired by eutrophication, $53 \%$ in Europe, $48 \%$ in North America, $41 \%$ in South America and $28 \%$ in Africa (Nyenje et al. 2010).

Several processes have been used to remove $\mathrm{P}$ from eutrophied freshwater bodies. Examples include chemical precipitation with aluminium, iron, calcium and industrial by-products (Genz et al. 2004; Kõiva et al. 2010; Lewandowski et al. 2003; Lan et al. 2006) and adsorption with clays (Yuan and $\mathrm{Wu} 2007$ ). Industrial by-products present a high removal capacity for P; however, they can contaminate the water with heavy metals. The use of aluminium and iron salts to precipitate $\mathrm{P}$ demands tight control of the $\mathrm{pH}$ to avoid dissolution of the precipitates; in addition, the parallel reactions that occur consume part of the chemicals, leading to the need of chemical overdose to guarantee the desired removal degree. Clay minerals have a tendency to disperse into very fine particles when applied to water bodies, which may cause an increase in turbidity for prolonged periods of time (Donnert and Salecker 1999; Hano et al. 1997; Miller 2005; Zeng et al. 2004; Zhang et al. 2009).

The present work investigated the removal of phosphate from water using a newly developed hybrid nanocomposite containing aluminium nanoparticles (HPN). The HPN results from a reaction between an organic and an inorganic component, the latter being the removal agent for P. HPNs were obtained by a sol-gel process. The chosen polymer was polypropylene grafted with maleic anhydride (PP-g-MA); two aluminium precursors, aluminium isopropoxide $\left(\mathrm{Al}(\mathrm{Pr}-\mathrm{i}-\mathrm{O})_{3}\right)$ and aluminium acetylacetonate $\left(\mathrm{Al}(\mathrm{acac})_{3}\right)$, were used. The experiments done in the present study comprised short-term batch tests to compare the $\mathrm{P}$ removal rates of the HPN with other materials and column experiments to assess the long-term attenuation capacity of the HPN under conditions of continuous P loadings.

\section{Materials and Methods}

\subsection{Materials and HPN Synthesis}

Two different HPNs were synthesised based on a sol-gel reaction in the melt. This reaction allows direct incorporation of aluminium nanoparticles into a polymeric matrix. PP-g-MA, provided by Crompton, and two aluminium precursors $\left(\mathrm{Al}(\mathrm{Pr}-\mathrm{i}-\mathrm{O})_{3}\right.$ and $\left.\mathrm{Al}(\mathrm{acac})_{3}\right)$, supplied by Sigma Aldrich and Acros Organics, respectively, were used. The HPN synthesized with $\mathrm{Al}(\mathrm{Pr}-\mathrm{i}-\mathrm{O})_{3}$ was named HPN-Pr, whilst the HPN synthesized with $\mathrm{Al}(\mathrm{acac})_{3}$ was named HPN-acac. The HPN was produced in the melt, in a batch mixer (Haake Rheomix OS600; volume, $60 \mathrm{~mL}$ ), equipped with two rotors running in a counter-rotating manner. The rotor speed was $50 \mathrm{rpm}$ and the set temperature was $180{ }^{\circ} \mathrm{C}$. The following procedure was adopted: first, the polymer pellets were introduced into the hot mixer and melted, and then the aluminium precursor was added in a ratio 1:1 (maleic anhydride/precursor) and the mixing proceeded. After $10 \mathrm{~min}$, the material was removed and crushed to a granular size between 100 and $300 \mu \mathrm{m}$. More detailed information on the synthesis and properties of HPN-Pr and HPN-acac can be found in Oliveira et al. (2012).

The density and the specific surface of HPN-Pr and $\mathrm{HPN}$-acac were similar for both materials, $1.23 \mathrm{~g} / \mathrm{cm}^{3}$ and $2 \mathrm{~m}^{2} / \mathrm{g}$, respectively.

\subsection{Reaction Extension and Chemical Properties of the HPNs}

\subsubsection{Reaction Extension}

The incorporation of aluminium nanoparticles into the HPNs was determined by infrared analysis (Fourier transform infrared, FTIR). Thin films were previously prepared by compression moulding of the HPNs in a hot press at $180^{\circ} \mathrm{C}$. The FTIR spectra of the materials were recorded using a PerkinElmer 1610 in transmission mode between 400 and $4,000 \mathrm{~cm}^{-1}$, with 32 scans and a resolution of $4 \mathrm{~cm}^{-1}$.

\subsubsection{Zero Point Charge}

The zero point charge is usually defined as the $\mathrm{pH}$ value at which a solid submerged in an electrolyte exhibits zero net electrical charge on the surface, as explained by Kosmulski (2002) and Smičiklas et al. (2000). To determine the zero point charge $\mathrm{pH}\left(\mathrm{pH}_{\mathrm{ZPC}}\right)$ of the HPN-Pr and HPN-acac, $0.1 \mathrm{~g}$ of each material was placed in $50 \mathrm{~mL}$ of $0.1 \mathrm{M} \mathrm{NaCl}$ solution (used as an inert electrolyte) with initial $\mathrm{pH}$ in the range of 2.0-12.0. The $\mathrm{pH}$ was adjusted by either the addition of chloridric acid or sodium hydroxide using an ORION pH meter (model 
420A). The experiments took place in sealed plastic Erlenmeyer flasks clamped into an orbital shaker at $100 \mathrm{rpm}$ and $22{ }^{\circ} \mathrm{C}$. Chemical equilibrium was attained after $24 \mathrm{~h}$ and the $\mathrm{pH}$ then measured. Experiments were done in triplicate.

\subsection{Phosphate Removal}

\subsubsection{Effect of $\mathrm{pH}$ on Phosphate Removal by HPNs}

The effect of $\mathrm{pH}$ on phosphate removal by both HPNPr and HPN-acac was studied by a batch contacting method as follows: $0.04 \mathrm{~g}$ of each material was placed in contact with $50 \mathrm{~mL}$ solution containing $1,000 \mu \mathrm{g} / \mathrm{L}$ $\mathrm{P}$ with initial $\mathrm{pH}$ in the range of 2.0-11.0. The tests were performed in triplicate, at $22^{\circ} \mathrm{C}$, under $100 \mathrm{rpm}$ for 5 days. The concentration of phosphate was measured in the beginning and at the end of the experiments by the ascorbic acid colorimetric method using a Shimadzu spectrophotometer (method 4500P-E, Standard Methods, Eaton et al. 1995). Potassium dihydrogenophosphate $\left(\mathrm{KH}_{2} \mathrm{PO}_{4}\right.$, Merck) was used as the phosphate source.

\subsubsection{Removal Capacity of Phosphorus by HPNs}

The phosphate saturation potential of the HPNs was assessed by a batch contacting method. In this method, $0.04 \mathrm{~g}$ of each material was contacted with $50 \mathrm{~mL}$ solution containing $1,000 \mu \mathrm{g} / \mathrm{L}$ P with initial $\mathrm{pH}$ of 6.0. The tests were done in triplicate, at $100 \mathrm{rpm}$ and $22{ }^{\circ} \mathrm{C}$, for 5 days. The concentration of phosphate was measured daily as previously described.

At the end of the tests, the aluminium concentration present in the solution was determined by the electrothermal atomic absorption spectrometric method using a Shimadzu AA-6880F spectrometer (method 3500Al-B, Standard Methods, 1995). The HPN that released the lowest amount of aluminium was selected for further studies.

The capacity of the HPN-Pr to remove polyphosphate was tested by the batch contacting method. In this method, $0.04 \mathrm{~g}$ the HPN-Pr was contacted with $50 \mathrm{~mL}$ solution containing $1,000 \mu \mathrm{g} / \mathrm{L}$ of polyphosphate with initial $\mathrm{pH}$ of 6.0 . The tests were done in triplicate, at $100 \mathrm{rpm}$ and $22{ }^{\circ} \mathrm{C}$, for 5 days. Pentasodiumtripolyphosphate $\left(\mathrm{Na}_{5} \mathrm{P}_{3} \mathrm{O}_{10} \cdot 6 \mathrm{H}_{2} \mathrm{O}\right.$, Sigma Aldrich) was used as the polyphosphate source. The concentration of phosphate was measured by the ascorbic acid colorimetric method after a digestion process, as previously described.

\subsubsection{Phosphate Adsorption Isotherm on $\mathrm{HPN}-\mathrm{Pr}$}

The extent of $\mathrm{P}$ adsorption from the solution was studied using a batch contacting method. The HPN that released the lowest amount of aluminium, HPN$\mathrm{Pr}$, was previously crushed to a granular size around $200 \mu \mathrm{m}$ and weighed in the range of 10-300 $\mathrm{mg}$. The weighed materials were contacted with $50 \mathrm{~mL}$ solution containing $10 \mathrm{mg} / \mathrm{L} \mathrm{P}$ with initial $\mathrm{pH}$ of 6.0. Adsorption took place in sealed plastic Erlenmeyer flasks clamped into an orbital shaker at $100 \mathrm{rpm}$ and $22{ }^{\circ} \mathrm{C}$ for 5 days. The tests were done in triplicate. At equilibrium, the concentration of phosphate in the solution was measured as previously described. The amount of $\mathrm{P}$ adsorbed on the HPN-Pr at equilibrium was calculated according to Eq. 1, where $X$ (in grams per kilogram) is the mass of $\mathrm{P}$ (in grams) removed per mass of HPN-Pr (in kilograms), $C_{\text {ini }}$ is the initial concentration of $\mathrm{P}$ (in grams per litre), $C_{\mathrm{eq}}$ is the equilibrium concentration of $\mathrm{P}$ (in grams per litre), $V$ is the solution volume (in litres), and $M$ is the mass of HPN-Pr (in kilograms).

$X=\left(C_{i n i}-C_{e q}\right) \cdot \frac{V}{M}$

\subsubsection{Column Test}

A column test was preformed to assess the long-term attenuation capacity of the HPN-Pr under a continuous $\mathrm{P}$ flow rate. A column of 90 and $35 \mathrm{~mm}$ (height and diameter, respectively) was packed with $17 \mathrm{~g}$ of HPNPr granules with sizes between 100 and $300 \mu \mathrm{m}$; the porosity of the bed was 0.19 . A solution with $1,000 \mu \mathrm{g} / \mathrm{L} \mathrm{P}$ was continuously pumped through the column at a flow rate of $1 \mathrm{~mL} / \mathrm{min}$ for 4 weeks. The time required for the solution to cross the column was calculated using Eq. 2.

$t=\frac{\pi \cdot r^{2} \cdot h \cdot \theta}{Q}$

where $t$ is the residence time (in hours), $r$ is the radius of the column (in centimetres), $h$ is the height of the HPN-Pr in the column (in centimetres), $\theta$ is the porosity of the HPN-Pr bed inside the column, and $Q$ is the flow rate (in millilitres per hour). 


\subsection{Regeneration and Recovery Study}

The HPN-Pr was cut into small squares of $2 \times 2 \mathrm{~mm}$ and saturated with phosphate. For that, $0.2 \mathrm{~g}$ of HPNPr was contacted with $50 \mathrm{~mL}$ solution containing $1,000 \mu \mathrm{g} / \mathrm{L} \mathrm{P}$ with initial $\mathrm{pH}$ of 6.0. The experiments were done in triplicate, at $100 \mathrm{rpm}$ and $22{ }^{\circ} \mathrm{C}$, for 5 days. The concentration of phosphate was measured at the beginning and at the end of the batch tests. To recover the adsorbed phosphate and regenerate the HPN-Pr, the material was washed with $0.5 \mathrm{M} \mathrm{NaOH}$ or $0.5 \mathrm{M} \mathrm{HCl}$ for $10 \mathrm{~s}$. The saturation and washing steps were repeated cyclically; in between, the material was washed with deionized water. As a comparison, the same procedure was done without the regeneration step. Finally, X-ray microanalysis mapping was performed on the HPN-Pr surface to evaluate its chemical composition. An energy-dispersive X-ray spectrometer (EDS) from Link eXL II attached to an electronic microscope (Oxford Instruments) was used.

\section{Results and Discussion}

\subsection{Chemical Properties}

The synthesis of HPN was based in a sol-gel reaction consisting of the incorporation of aluminium nanoparticles into a polymeric matrix via a hydrolysis condensation reaction, as illustrated in Eq. 3.

$$
\begin{aligned}
& P P-g-M A+\operatorname{Al}(\mathrm{Pr}-i-O)_{3}+2 \mathrm{H}_{2} \mathrm{O} \\
& \quad \rightarrow P P-g-\operatorname{MAAl}(\mathrm{OH})_{2}+3 \mathrm{Pr}-i-\mathrm{OH}
\end{aligned}
$$

where PP-g-MA is the organic compound, $\mathrm{Al}(\mathrm{Pr}-\mathrm{i}-\mathrm{O})_{3}$ the aluminium precursor, $\mathrm{PP}-\mathrm{g}-\mathrm{MAAl}(\mathrm{OH})_{2}$ the final HPN-Pr, and Pr-i-OH a by-product of the reaction.

The FTIR spectra provided information on the hydrolysis condensation of the aluminium precursor and, thus, the new bonds formed. The spectra obtained for both HPNs are shown in Fig. 1. To evaluate the extension of PP-g-MAAl $(\mathrm{OH})_{2}$ formation, it is important to analyse two spectral ranges: $3,500-3,000 \mathrm{~cm}^{-1}$, where the $\mathrm{OH}$ stretching mode appears, and 1,000$400 \mathrm{~cm}^{-1}$, where the Al-O stretching mode occurs. In the spectrum of HPN-Pr, a very broad band appeared around $3,450 \mathrm{~cm}^{-1}$ and another between 1,000 and $400 \mathrm{~cm}^{-1}$. Conversely, the $\mathrm{OH}$ or $\mathrm{Al}-\mathrm{O}$ stretching modes were not observed in the spectrum of
HPN-acac. These results suggested that the precursor containing smaller organic groups $\left(\mathrm{Al}(\mathrm{Pr}-\mathrm{i}-\mathrm{O})_{3}\right)$ promoted the formation of aluminium nanoparticles chemically bonded to the polymer backbone. On the contrary, Al $(\mathrm{acac})_{3}$ did not react with the polymer, as can be concluded by the presence of two bands at 1,520 and $1,580 \mathrm{~cm}^{-1}$ characteristic of the organic group (acac) connected to the aluminium. HPN-acac consists of a physical mixture of polymer and aluminium precursor.

The $\mathrm{pH}$ of zero point charge $\left(\mathrm{pH}_{\mathrm{ZPC}}\right)$ of the HPNs studied in the present work was derived from Fig. 2. In the $\mathrm{pH}$ interval from 5.0 to 9.0 , the $\mathrm{pH}$ at equilibrium was similar to the $\mathrm{pH}_{\mathrm{ZPC}}$, suggesting that the surface of both HPNs exhibited amphoteric properties acting as a buffer in this $\mathrm{pH}$ interval. No significant differences in charge density were observed between both HPNs, and the $\mathrm{pH}_{\mathrm{ZPC}}$ values obtained ranged from 7.0 to 8.0 .

\subsection{P Removal}

\subsubsection{Effect of $p H$ on Phosphate Removal}

The effect of $\mathrm{pH}$ in the removal capacity of phosphate by both HPNs is shown in Fig. 3. HPN-Pr presented a maximum removal capacity in the $\mathrm{pH}$ range from 2.0 to 6.5. For $\mathrm{pH}$ values near its $\mathrm{pH}_{\mathrm{ZPC}}(7.0-8.0)$, a drastic reduction in the phosphate removal capacity was observed, which can be due to the change of the surface charge from positive $(+)$ to negative $(-)$. Also, at high $\mathrm{pH}$ values, a decrease in the phosphate removal capacity due to $\mathrm{OH}^{-}$competition was expected. HPNacac depicted a maximum phosphate removal capacity in a narrower $\mathrm{pH}$ range, between 6.0 and 8.5. Moreover, for $\mathrm{pH}$ values above the $\mathrm{pH}_{\mathrm{ZPC}}$, a reduction in the phosphate removal capacity was detected. A similar behaviour was described for $\mathrm{Al}(\mathrm{OH})_{3}$ by Galarneu and Gehr (1997). Since HPN-acac consists of a physical mixture of polymer and aluminium precursor, the latter, when immersed in water, rapidly hydrolysed, forming $\mathrm{Al}(\mathrm{OH})_{3}$. This might explain the different behaviour.

Taking into account that the $\mathrm{pH}$ values found in freshwater bodies range from 2.5 to 8.2 (Claret et al. 2003; MacLeod and Whitfield 1996; Markich and Brown 1998; Olías et al. 2004), the HPN-Pr (7.22\% oxide composition) has a broader application to remove phosphate compared to that of HPN-acac (2.84\% oxide composition). 
Fig. 1 FTIR spectra of HPN-Pr and HPN-acac recorded between 400 and $4,000 \mathrm{~cm}^{-1}$

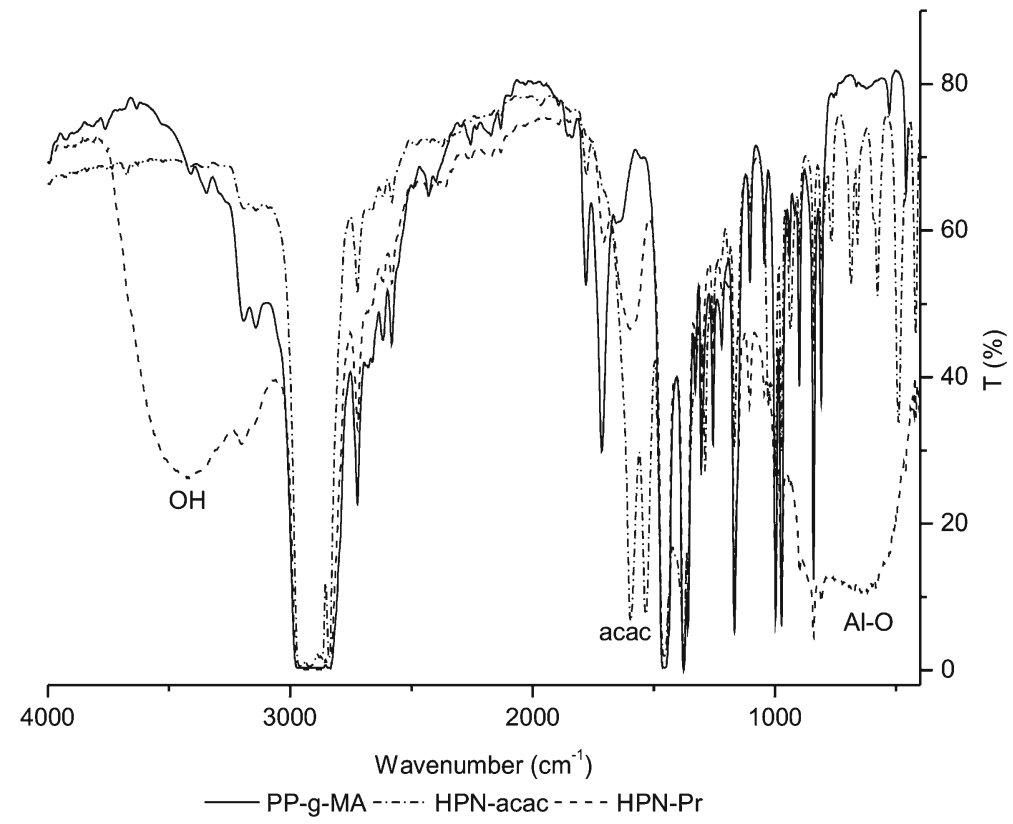

\subsubsection{Removal of Phosphorus by HPNs}

The kinetic curves of phosphorus removal by both HPNs are depicted in Fig. 4. A clear difference can be observed between both materials; the HPN-acac removed all phosphate in $<24 \mathrm{~h}$, whilst the HPN-Pr only lowered the phosphate concentration from 1,000 to $400 \mu \mathrm{g} / \mathrm{L} \mathrm{P}$ in 5 days. The phosphate removal capacity was $0.80 \pm 0.01 \mathrm{mg} / \mathrm{g}$ for HPN-Pr and $1.27 \pm 0.02 \mathrm{mg} / \mathrm{g}$ for HPN-acac.

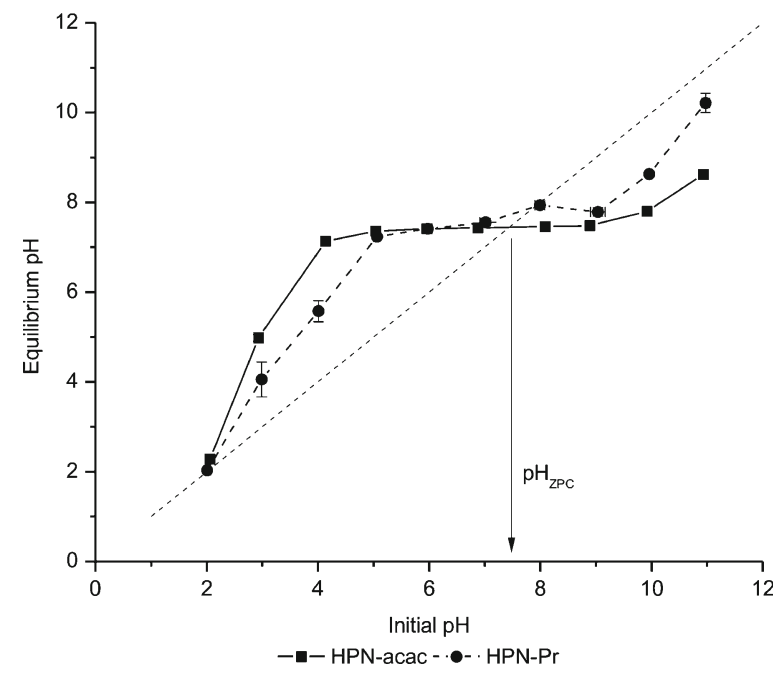

Fig. 2 Determination of point of zero charge for HPN-Pr and $\mathrm{HPN}$-acac at $22 \pm 1{ }^{\circ} \mathrm{C}$ for $24 \mathrm{~h}$ under $100 \mathrm{rpm}$
Bauxite and shale, both argillaceous rocks, presented a phosphate removal capacity of the same order of magnitude of HPN-Pr, 0.36 and $0.73 \mathrm{mg} / \mathrm{g}$, respectively. Previous studies showed that activated alumina, which is pure $\mathrm{Al}_{2} \mathrm{O}_{3}$, presented a phosphate removal capacity of $7 \mathrm{mg} / \mathrm{g}$, which is almost ten times higher than that of HPN-Pr (Drizo et al. 1999; Sakadevan and Bavor 1998). Xiong and Peng (2011), using ferrihydrite-modified diatomite $\left(89.2 \% \mathrm{SiO}_{2}\right.$ and $\left.4 \% \mathrm{Al}_{2} \mathrm{O}_{3}\right)$, achieved a total phosphorus removal efficiency of $85 \%$ under anoxic conditions with an initial phosphorus concentration of

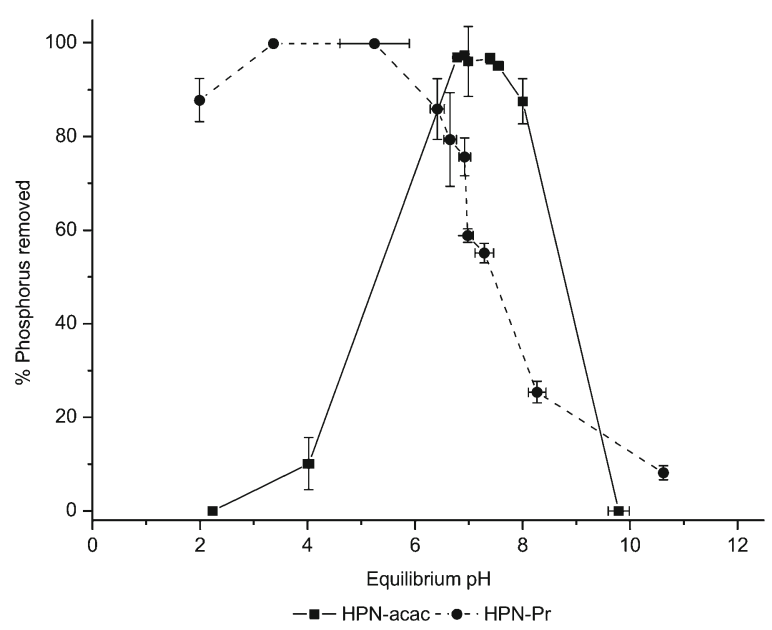

Fig. 3 Influence of $\mathrm{pH}$ on HPN phosphate removal capacity at $22 \pm 1{ }^{\circ} \mathrm{C}$ for 5 days under $100 \mathrm{rpm}$ 
$113 \mu \mathrm{g} / \mathrm{L}$. However, when comparing the phosphate removal capacity of HPN-Pr with other aluminiumbased materials described in literature (Table 1), we need to keep in mind that only a fraction of the HPN is active to remove phosphate ( $8 \%$ ). Clipnotiolite, a zeolite based on $\mathrm{SiO}_{2}(65.9 \%)$ and $\mathrm{Al}_{2} \mathrm{O}_{3}(12.97 \%)$, presented a phosphate removal capacity of $2.15 \mathrm{mg} / \mathrm{g}$, which is higher than that of both HPNs developed in the present study (6.2\% for HPN-Pr and $3.9 \%$ for HPN-acac; Sakadevan and Bavor 1998). This fact might be due to the very high porosity and, consequently, internal surface area of zeolites. Also, a mesoporous silica has been functionalized with $\mathrm{Cu}$ and $\mathrm{Fe}$ to remove phosphate from water (Chouyyok et al. 2010). The removal capacity of these sorbents is much higher than that of both HPNs, which is due, again, to their huge internal area $\left(169 \mathrm{~m}^{2} / \mathrm{g}\right)$. Although it is very advantageous to use sorbents containing very small pores to maximize the removal capacity, the tiny pores with a size of angstroms might be immediately blocked when used in natural systems, where solid particles that have higher dimensions than the pores are present (for example, bacteria have, on average, $1 \mu \mathrm{m}$ ), resulting in a fast decrease of the removal capacity. The approach followed in the present work was to produce a polymeric sorbent with a rough surface but without internal pores whose surface area can be improved and optimized via a 3D structure. Future studies will be dedicated to improve the design of the HPN-Pr.

To assess the feasibility of both HPNs to remediate eutrophic freshwater bodies without further contamination, the concentration of aluminium was assessed after a batch contacting test. The results revealed that $6.9 \times 10^{-3} \pm 1.9 \times 10^{-3} \mathrm{mg} / \mathrm{L} \mathrm{Al}$ and $5.5 \pm 0.4 \mathrm{mg} / \mathrm{L} \mathrm{Al}$ were obtained with HPN-Pr and HPN-acac, respectively. As shown in the FTIR analysis and the $\mathrm{pH}$ test, the $\mathrm{Al}$ $(\mathrm{acac})_{3}$ precursor did not form covalent bonds with the

Table 1 Comparison of the phosphate removal capacity of HPNs with other materials describes in the literature

\begin{tabular}{lc}
\hline & Phosphate removed $(\mathrm{mg} / \mathrm{g})$ \\
\hline HPN-Pr & 0.80 \\
HPN-acac & 1.27 \\
Bauxite & 0.36 \\
Shale & 0.73 \\
Alumina & 7.00 \\
Clipnotiolite & 2.15 \\
\hline
\end{tabular}

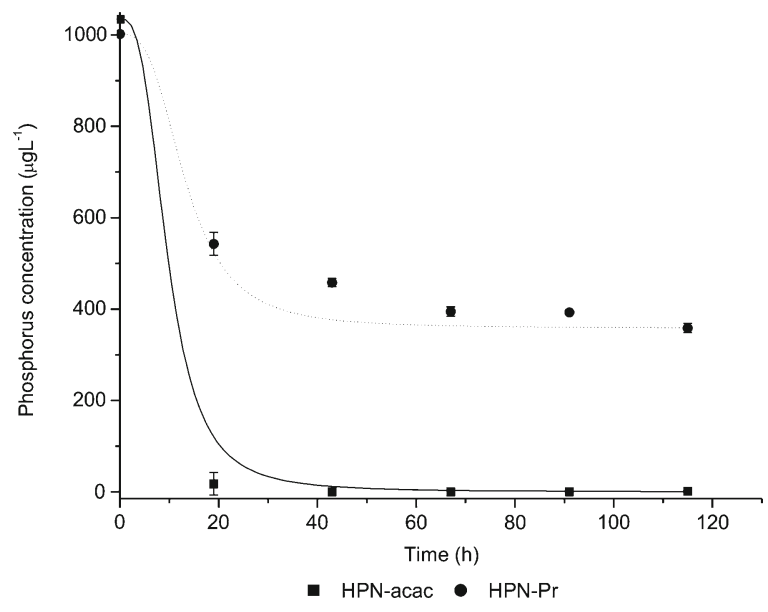

Fig. 4 Phosphorus concentration profiles along time for both HPNs at $22 \pm 1{ }^{\circ} \mathrm{C}$ for 5 days under $100 \mathrm{rpm}$ and initial $\mathrm{pH}$ of 6.0

polymer backbone and can easily hydrolyse into $\mathrm{Al}$ $(\mathrm{OH})_{3}$, provoking water contamination with aluminium. Therefore, the application of HPN-acac in freshwater bodies to remove phosphate is not recommended due to the water contamination with aluminium. Thus, HPN-Pr seems to be an interesting solution to remediate eutrophic freshwater bodies due to its stability and reasonable capacity to remove phosphate.

Besides phosphate, polyphosphate is also present in water bodies and gradually hydrolyses into phosphate, contributing to the excessive growth of algae (Hongshan and Songqiang 2003; Hupfer et al. 2004). For this reason, the polyphosphate removal capacity of HPN-Pr was assessed from its concentration profile (data not shown). The amount of polyphosphate removed was $0.52 \pm 0.01 \mathrm{mg} / \mathrm{g} P$ and occurred mainly in the first $71 \mathrm{~h}$. This value was slightly lower compared to that of phosphate. This fact might be related to the size of the anions, orthophosphate $\left(\mathrm{H}_{2} \mathrm{PO}_{4}{ }^{-}, \mathrm{HPO}_{4}{ }^{2-}\right.$ and $\mathrm{PO}_{4}{ }^{3-}$ ) being smaller and less complex than polyphosphate $\left(\mathrm{P}_{2} \mathrm{O}_{7}{ }^{1-}\right)$; thus, orthophosphate can more easily be adsorbed (Georgantas and Grigoropoulou 2007). Razali et al. (2007) reported a polyphosphate removal capacity of $7.4 \mathrm{mg} / \mathrm{g}$ for a by-product generated during the production of drinking water. This was to be expected because this sludge was mainly constituted of aluminium $\left(46 \%\right.$ as $\left.\mathrm{Al}_{2} \mathrm{O}_{3}\right)$.

\subsubsection{P Adsorption Isotherm on HPN-Pr}

The adsorption isotherm of phosphate on the HPN-Pr was determined to assess the adsorption mechanism. The 


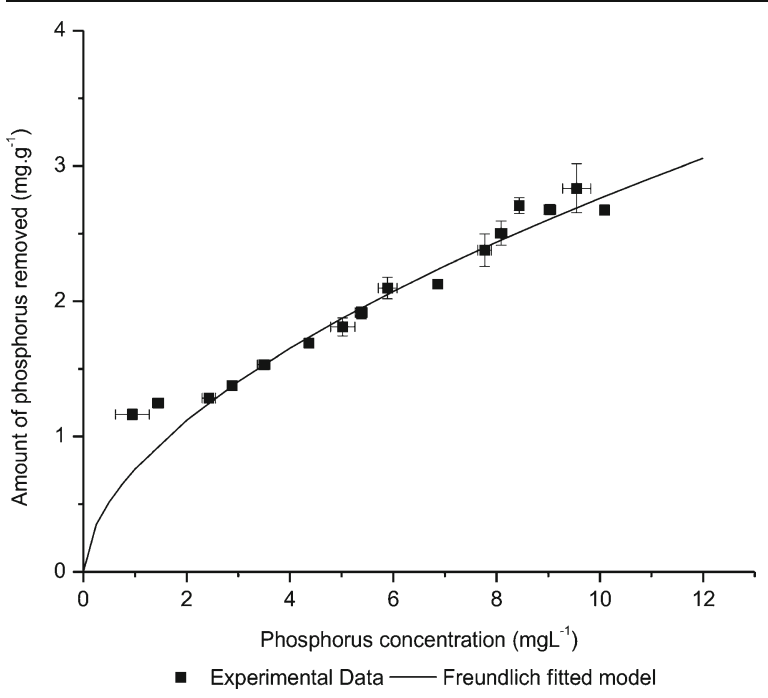

Fig. 5 Adsorption isotherm of phosphate onto HPN-Pr at initial $\mathrm{pH}$ of $6.0,22 \pm 1{ }^{\circ} \mathrm{C}$ for 5 days under $100 \mathrm{rpm}$

experimental data were fitted using the Freundlich model (Fig. 5 and Eq. 4) with a correlation coefficient of 0.986.

$$
S=0.76 \cdot[C]^{0.56}
$$

where $S$ is the amount of $\mathrm{P}$ adsorbed (in milligrams per gram) and $C$ the equilibrium concentration (in milligrams per litre). The values of the equation constants, $K$ and $n$, calculated were $0.76 \mathrm{mg}^{1-n} \cdot \mathrm{L}^{n} / \mathrm{g}$ and 1.79 , respectively. In general, it is considered that the adsorption capacity of the adsorbent improves with the increase of the $K$ value (Kuroda 1987). The $K$ value

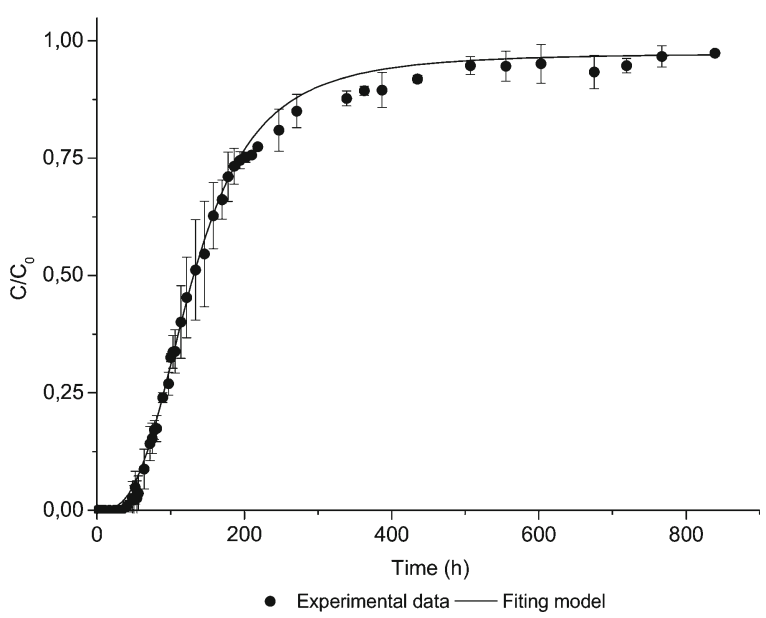

Fig. 6 Relative phosphate concentration $\left(C / C_{0}\right)$ at the effluent of a column as a function of time for HPN-Pr at $22 \pm 1{ }^{\circ} \mathrm{C}$ for 4 weeks at $1 \mathrm{~mL} / \mathrm{min}$

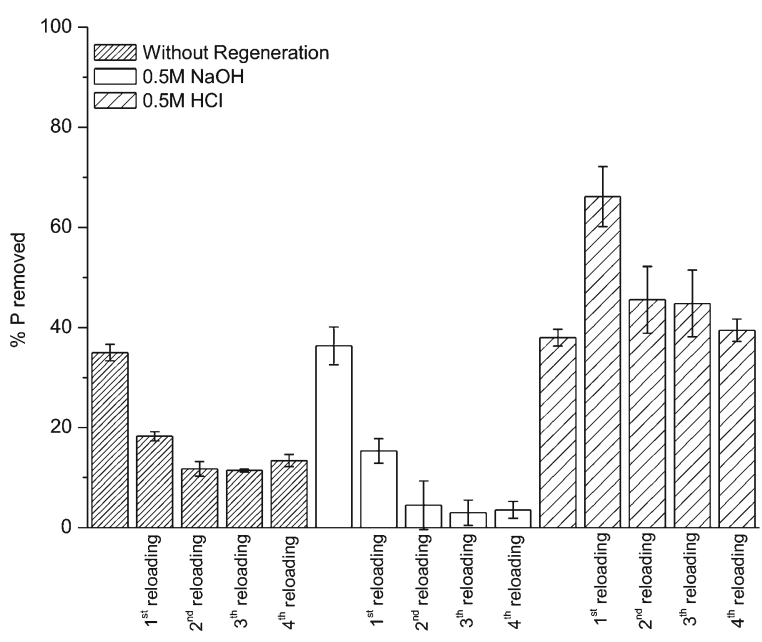

Fig. 7 Phosphate removal capacity of HPN-Pr with and without regeneration

obtained in the present study was higher than that reported by Kuroda for the adsorption of phosphate onto aluminium oxide (0.2). The $n$ value obtained was higher than 1 , indicating that $\mathrm{P}$ adsorption on HPN-Pr was a favourable process (Benyoucef and Amrani 2011).

\subsubsection{Column Test}

The removal of phosphate in a packed bed column with HPN-Pr along 30 days is depicted in Fig. 6. The residence time $(T)$ determined was around $29 \mathrm{~min}$. The removal efficiency of phosphate was $100 \%$ during the first $40 \mathrm{~h}$ of operation. It decreased to $50 \%$ at the end of $134 \mathrm{~h}$, and the column reached complete saturation at $500 \mathrm{~h}$. The removal capacity determined in the column test was $0.63 \mathrm{mg} / \mathrm{g}$, which was lower than that obtained in batch essays. This result might be explained by the low porosity of the particles (0.19) and the very small HPN-Pr particles $(100-300 \mu \mathrm{m})$. Since they are very small, they can be easily compacted; this would decrease the contact between the material and the solution, resulting in a lower removal capacity. Future studies will test materials with

Table 2 Aluminium and oxygen present on the surface of HPN-Pr before and after the acidic and alkaline regeneration steps determined by EDS

\begin{tabular}{lcc}
\hline HPN & $\mathrm{Al}(\%)$ & $\mathrm{O}(\%)$ \\
\hline Virgin & 7.22 & 27.55 \\
HCl regeneration & 7.30 & 27.46 \\
NaOH regeneration & 3.65 & 23.37 \\
\hline
\end{tabular}


higher granulometry. In a similar study with alum residues, $0.48 \mathrm{mg} / \mathrm{g}$ of $\mathrm{P}$ was removed from an aquaculture process water at $\mathrm{pH} 7.0$ (Mortula and Gagnon 2009).

\subsection{Regeneration Study}

The regeneration of HPN-Pr and recovery of phosphate after the removal step is very important from the economical and environmental points of view. This process should be simple, fast and inexpensive. The removal capacity of HPN-Pr was regenerated by washing either with $\mathrm{HCl}$ or $\mathrm{NaOH}$ for $10 \mathrm{~s}$. Four successive cycles of saturation and washing were made with the same HPN-Pr. The percentage of P removed in each cycle is depicted in Fig. 7.

Cyclic saturation of the HPN-Pr without intermediary regeneration steps revealed that the material continues to present adsorption capacity. This fact might be due to the existence of a phosphate concentration gradient between the solution and the solid phase. This result is in agreement with the Freundlich adsorption model that best described phosphate adsorption on HPN-Pr. According to the literature, the Freundlich model describes the adsorption process as a multilayer, where phosphate continues to adsorb after reaching the saturation in the presence of a concentration gradient (Genz et al. 2004; Zhang et al. 2011).

The regeneration of the saturated HPN-Pr with $\mathrm{HCl}$ was effective, whilst with $\mathrm{NaOH}$ was not successful. In the first alkaline washing step, the adsorption capacity of the HPN-Pr decreased significantly; it was maintained constant in the next washing steps, but considerably lower than that of the initial material. Conversely, an increase in the phosphate adsorption capacity was observed in the first acidic washing step. Between the first and the second washing steps, a decrease in the amount of phosphate adsorbed was observed, and then was kept almost constant and similar to the adsorption capacity of the initial HPN-Pr. The increase in the phosphate adsorption capacity observed in the first acidic treatment might be due to the removal of chemical groups connected to aluminium by weak bonds (e.g. $\mathrm{OH}$ ), which would raise the adsorption capacity of HPN-Pr. The virgin HPN-Pr had an aluminium content around $7.2 \%$; the alkaline washing step caused a decrease in the amount of aluminium nanoparticles to $3.6 \%$ (Table 2). This might have been caused by the breakdown of weak chemical bonds between aluminium atoms in the surface of the HPN-Pr. Conversely, the acidic washing did not cause a variation in the percentage of aluminium in the surface of HPN-Pr, where $7.3 \%$ was detected.

The phosphate species present in solution are dependent on $\mathrm{pH}$ (Oliveira et al. 2011). Around $\mathrm{pH}$ 7.0, $\mathrm{H}_{2} \mathrm{PO}_{4}{ }^{-}$is the predominant species in solution (a weak acid with a $K_{\mathrm{a}}$ value of 7.2) and becomes a non-charged species in contact with an acidic solution (Awual et al. 2011). This might explain the fact that phosphate was desorbed when HPN-Pr was washed with $\mathrm{HCl}$, the reaction being as follows:

$\left(-\mathrm{AlPO}_{4}\right)^{-}+3 \mathrm{H}^{+} \rightleftarrows-\mathrm{Al}^{2+}+\mathrm{H}_{3} \mathrm{PO}_{4}$

\section{Conclusions}

The hybrid nanocomposites studied in the present work were revealed as new and effective materials to remove phosphorus from eutrophic natural waters. Whilst HPNPr removes $0.80 \pm 0.01 \mathrm{mg} \mathrm{P} / \mathrm{g}$ at the $\mathrm{pH}$ interval from 2.0 to $6.5, \mathrm{HPN}$-acac removes $1.27 \pm 0.02 \mathrm{mg} \mathrm{P} / \mathrm{g}$ at the $\mathrm{pH}$ interval of $6.0-8.5$. However, determination of the aluminium concentrations in batch tests indicated that HPN-acac transferred higher levels of this ion to the solution, which makes this unviable for natural applications. HPN-Pr was shown to be chemically stable, with adsorption mechanism described by the Freundlich adsorption model. Moreover, HPN-Pr could be regenerated by washing it with $0.5 \mathrm{M} \mathrm{HCl}$. Regeneration allows the recovery of phosphorus adsorbed by HPN-Pr, which can be again introduced on a commercial cycle, contributing this way to the sustainability of this mineral resource which, each time, is scarcer.

HPN-Pr is a material used to treat natural eutrophic waters preferentially by proper application; compared with other common phosphorus removal agents, it does not increase the water turbidity and sludge production or contaminate with toxic compounds.

Acknowledgments The authors acknowledge the Foundation for Science and Technology (FCT) Project SFRH/BD/39085/ 2007 for the financial support.

\section{References}

Awual, M. R., Jyo, A., El-Safty, S., Tamada, M., \& Seko, N. (2011). A weak-base fibrous anion exchanger effective for rapid phosphate removal from water. Journal of Hazardous Materials, 188, 264-171. 
Benyoucef, S., \& Amrani, M. (2011). Adsorption of phosphate ions onto low cost Aleppo pine adsorbent. Desalination, 271, 231-236.

Carmichael, W. W. (1991). Toxic freshwater blue-green algae (cyanobacteria): an overlooked health threat. Health Environmental Digest, 5, 1-4.

Chouyyok, W., Wiacek, R. J., Pattamakomsan, K., Sangvanich, T., Grudzien, R. M., \& Fryxell, G. E. (2010). Phosphate removal by anion binding on functionalized nanoporous sorbents. Environmental Science and Technology, 44, 3073-3078.

Claret, F., Schäfer, T., Bauer, A., \& Buckau, G. (2003). Generation of humic and fulvic acid from Callovo-Oxfordian clay under high alkaline conditions. Science of the Total Environment, 317, 189-200.

Correll, D. L. (1999). Phosphorus: a rate limiting nutrient in surface waters. Poultry Science, 78, 674-682.

Donnert, D., \& Salecker, M. (1999). Elimination of phosphorus from municipal and industrial waste water. Water Science and Technology, 40, 195-202.

Drizo, A., Frost, C. A., Grace, J., \& Smith, K. A. (1999). Physicalchemical screening of phosphate removing substrates for use in constructed wetland systems. Water Research, 33, 35953602 .

Eaton, A. D., Clesceri, L. S., \& Greenberg, A. E. (1995). Standard methods for the examination of water and wastewater (19th ed., pp. 4-113-4-114). Washington, DC: American Public Health Association.

Galarneu, E., \& Gehr, R. (1997). Phosphorus removal from wastewaters: experimental and theoretical support for alternative mechanism. Water Research, 31, 328-338.

Genz, A., Kornmüller, A., \& Jekel, M. (2004). Advanced phosphorus removal from membrane filtrates by adsorption on activated aluminium oxide and granulated ferric hydroxide. Water Research, 38, 3523-3530.

Georgantas, D. A., \& Grigoropoulou, H. P. (2007). Orthophosphate and metaphosphate ion removal from aqueous solution using alum and aluminium hydroxide. Journal of Colloid and Interface Science, 315, 70-79.

Hano, T., Takanashi, H., Hirata, M., Urano, K., \& Eto, S. (1997). Removal of phosphorus from wastewater by activated alumina adsorbent. Water Science and Technology, $35,39-46$.

Hickey, C. W., \& Gibbs, M. M. (2009). Lake sediment phosphorus release management - decision support and risk assessment framework. New Zealand Journal of Marine Freshwater, 43, 819-856.

Hongshan, L., \& Songqiang, L. (2003). Biochemical mechanism of the eutrophication and its prevention - the deep treatment of wastewater and its denitrification and dephosphorization. Marine Science Bulletin, 5, 32-39.

Hupfer, M., Rübe, B., \& Schmieder, P. (2004). Origin and diagenesis of polyphosphate in lake sediments: a ${ }^{31} \mathrm{P}-\mathrm{NMR}$ study. Limnology and Oceanography, 49, 1-10.

Kõiva, M., Liirab, M., Mandera, U., Mõtlepb, R., Vohlaa, C., \& Kirsimäe, K. (2010). Phosphorous removal using Ca-rich hydrated oil shale ash as filter material. The effect of different phosphorus loadings and wastewater compositions. Water Research, 44, 5232-5239.

Kosmulski, M. (2002). The pH-dependent surface charging and the points of zero charge. Journal of Colloid and Interface Science, 253, 77-87.
Kuroda, D. (1987). Simultaneous adsorption of phosphate and ammonium ions from industrial wastewater onto the same adsorbent. Kagaku To Kogyo, 61, 378-383.

Lan, Y. Z., Zhang, S., Wang, J. K., \& Smith, R. W. (2006). Phosphorous removal using steel slag. Acta Metallurgica Sinica (English Letters), 19, 449-554.

Lewandowski, J., Schauser, I., \& Hupfer, M. (2003). Long term effects of phosphorus precipitations with alum in hypereutrophic Lake Susser See (Germany). Water Research, 37, 3194-3204.

MacLeod, C., \& Whitfield, P. H. (1996). Seasonal and long-term variations in water quality of the Columbia River at Revelstoke. B.C. Northwest Science, 70, 55-65.

Markich, S. J., \& Brown, P. L. (1998). Relative importance of natural and anthropogenic influences on the fresh surface water chemistry of the Hawkesbury-Nepean River, southeastern Australia. Science of the Total Environment, 217, 201-230.

Miller, N. (2005). Locally available adsorbing materials, sediment sealing and flocculants for chemical remediation of lake and stream. Analytical \& Environmental Consultants.

Mortula, M. M., \& Gagnon, G. A. (2009). Alum residuals as a low technology for phosphorus removal from aquaculture processing water. Aquacultural Engineering, 36, 233-238.

Nyenje, P. M., Foppen, J. W., Uhlenbrook, S., Kulabako, R., \& Muwanga, A. (2010). Eutrophication and nutrient release in urban areas of sub-Saharan Africa-a review. Science of the Total Environment, 408, 447-455.

Olías, M., Nieto, J. M., Sarmiento, A. M., Cerón, J. C., \& Cánovas, C. R. (2004). Seasonal water quality variations in a river affected by acid mine drainage: the Odiel River (south west Spain). Science of the Total Environment, 333, 267-281.

Oliveira, M., Ribeiro, D., Nobrega, J. M., Machado, A. V., Brito, A. G., \& Nogueira, R. (2011). Removal of phosphorus from water using active barriers: $\mathrm{Al}_{2} \mathrm{O}_{3}$ immobilized on to polyolefins. Environmental Technology, 32, 989-995.

Oliveira, M., Nogueira, R., Machado, A.V. (2012). Synthesis of aluminium nanoparticles in a PP matrix during melt processing: effect of the alkoxide organic chain. React. and Funct. Poly. (in press).

Razali, M., Zhao, Y. Q., \& Bruen, M. (2007). Effectiveness of a drinking-water treatment sludge in removing different phosphorus species from aqueous solution. Separation and Purification Technology, 55, 300-306.

Sakadevan, K., \& Bavor, H. J. (1998). Phosphate adsorption characteristics of soils, slags and zeolite to be used as substrate in constructed wetland systems. Water Research, 32, 393-399.

Selman, M., Greenhalg, S. (2009). Eutrophication: polices, action, and strategies to address nutrient pollution. World Resources Institute, No. 3.

Smičiklas, I. D., Milonjić, S. K., Pfendt, P., \& Raičević, S. (2000). The point of zero charge and sorption of cadmium(II) and strontium(II) ions on synthetic hydroxyapatite. Separation and Purification Technology, 18, 185-194.

Xiong, W., \& Peng, J. (2011). Laboratory-scale investigation of ferrihydrite-modified diatomite as a phosphorus coprecipitant. Water, Air, and Soil Pollution, 215, 645-654. 
Yuan, G., \& Wu, L. (2007). Allophane nanoclay for the removal of phosphorus in water and wastewater. Science and Technology of Advanced Materials, 8, 60-62.

Zeng, L., Li, X., \& Liu, J. (2004). Adsorptive removal of phosphate from aqueous solutions using iron oxide tailings. Water Research, 38, 1318-1326.

Zhang, G., Liu, H., Liu, R., \& Qu, J. (2009). Removal of phosphate from water by a Fe-Mn binary oxide adsorbent. Journal of Colloid and Interface Science, 335, 168-174.
Zhang, J., Shen, Z., Mei, Z., Li, S., \& Wang, W. (2011). Removal of phosphate by Fe-coordinated amino-functionalized 3D mesoporous silicates hybrid materials. Journal of Environmental Sciences, 23, 199-205.

Zheng, S., Chen, J., Jiang, X., \& Li, X. (2011). A comprehensive assessment on commercially-available standard anion resins for tertiary treatment of municipal wastewater. Chemical Engineering Journal, 169, 194199. 